\title{
A University-Industry Collaborative Entrepreneurship Education Program as a Trading Zone: The Case of Osaka University
}

\author{
Koichi Nakagawa, Megumi Takata, Kosuke Kato, \\ Terumasa Matsuyuki, and Toshihiko Matsuhashi
}

\author{
"Collaboration is important not just because it's a better") \\ way to learn. The spirit of collaboration is penetrating \\ every institution and all of our lives. So learning to \\ collaborate is part of equipping yourself for effectiveness, \\ problem solving, innovation and life-long learning in an \\ ever-changing networked economy.
}

Don Tapscott

Business executive, author, and consultant

\begin{abstract}
Two complementary problems are that busy practitioners find it difficult to access academic knowledge and university students lack practical experience. University-industry collaborative education is a potential solution for both of these problems by bringing together theoretical insights from universities and experiential know-how from industry. However, university-industry collaborative education has not been sufficiently studied to offer clear frameworks and mechanisms to foster effective knowledge exchanges between these two groups. In this article, we propose the metaphor of a "trading zone" as a potential analytical framework for implementing this method of education. Applying this framework to the analysis of a university-industry collaborative education program, this study proposes that the exchange of knowledge between students and practitioners is the essential learning experience and that it is made more meaningful by the heterogeneity between students and practitioners. The shared language provided by the program and those who deliver it make the exchanges efficient, and the temporary and extraordinary nature of the program accelerate those exchanges. Here, we analyze the case of Osaka University in Japan to illustrate the framework and develop associated propositions to encourage further study and validation of the framework.
\end{abstract}

\section{Introduction}

To foster entrepreneurship and its skills, both formal education in novel theory and experiential learning in practical fields are needed Academic theory gives us rational and logical ways of thinking about technologies and management, and experience tells us how they work in practice (Etzkowitz, 2004; Gibb, 1996; Ollila \& Williams-Middleton, 2011). However, conventional education programs provided by universities typically focus only on the theoretical side. Thus, in recent years, universities have tried to introduce experiential learn- ing to help students understand how theories can be applied to the real world (Gibb, 1996). Among these efforts, university-industry collaboration, which encourages two-way interactions and learning, holds great promise (Dooley \& Kirk, 2007; Perkmann \& Walsh, 2007) because university students can obtain rich and insightful experiential know-how from industry-side participants and practitioners can gain theoretical knowledge from students. Furthermore, the effectiveness of university-industry collaboration for entrepreneurship education is enhanced particularly through project-based learning (Blumenfeld et al., 1991), where 


\title{
A University-Industry Collaborative Entrepreneurship Education Program
}

\author{
Koichi Nakagawa, Megumi Takata, Kosuke Kato, Terumasa Matsuyuki, and Toshihiko Matsuhashi
}

both university students and industrial practitioners jointly tackle a social, business, or technological problem. Examples of entrepreneurship education through university-industry collaboration can be seen in several universities in diverse countries (Etzkowitz \& Leydesdorff, 2000; Lundqvist \& Williams-Middleton, 2013).

Although past studies have indicated that university-industry collaboration can be an effective approach to entrepreneurial training because it can realize the combination of university theory and practical experiences, we know little about how participants truly interact each other, how exactly this approach facilitates entrepreneurship, and how we can improve its performance. In short, the field lacks a validated framework to support the effective implementation of the approach. Hence, the objectives of our study were: i) to propose a potential framework that can capture the university-industry collaboration approach to entrepreneurship education and ii) to provide qualitative and quantitative evidence of its effectiveness.

The rest of this article is structured as follows. First, we briefly review the relevant literature on entrepreneurship education and university-industry collaboration. Next, we introduce our method of insider action research and our research site: Osaka University, Japan, and its Technology Entrepreneurship and Commercialization program. Then, we present the results of our qualitative and quantitative analyses of the case. Through our discussion of the case analysis of the program at Osaka University, we next apply the metaphor of a "trading zone" (Galison, 1997) as a useful framework for and entrepreneurship education program based on university-industry collaboration. Finally, based on the case and its analysis, we offer several propositions to encourage further study and validation of the framework.

\section{Literature Review: Entrepreneurship Educa- tion and University-Industry Collaboration}

Considering their technology bases, sophisticated problem-solving methods, and skillful and ambitious students, universities can undertake more initiatives in innovation (Etzkowitz, 2004; Etzkowitz and Leydesdorff, 2000). As Etzkowitz and Leydesdorff (2000) explain the role of the university in their triple helix model, nowadays the industry-government dyad is insufficient in realizing industrial innovation, and a university-industry-government triad is needed to address the needs of today's knowledge society.
Given the new role for the university in relation to industry and government, facilitating and encouraging entrepreneurship becomes an important part of its mandate (Gibb, 1996; Ollila \& Williams-Middleton, 2011). Traditional management education focuses on the administration of hierarchical organizations and it tends to foster risk-averting decision making, and students as well as practitioners have become used to this administrative way of thinking. In contrast, the goal of entrepreneurship education is to develop skills and attributes that enable the realization of opportunity (Rasmussen \& Sørheim, 2006). Thus, to undertake a new and expanding role in innovation, universities have started their own entrepreneurship education programs (Barr et al., 2009; Janssen et al., 2007; Meyer et al., 2011).

Among the many and diverse approaches to entrepreneurship education, Dooley and Kirk (2007) consider university-industry collaboration to be effective and well suited to entrepreneurship training because, by nature, it combines the strengths of business entities with those of research and education institutions. As Gibb (1996) discussed, in entrepreneurship education, opportunities for experiential learning are needed for learners to understand realistic approaches to innovation and to nourish and challenge their minds. Ollila and Williams-Middleton (2011) proposed that the integration of conventional university education and a new experiential approach is desirable because they complement each other. The former encourages the problemoriented thinking and the latter fosters solution-oriented thinking, and both are beneficial in innovation activities.

Although research into university-industry collaboration for educational purposes is limited, a few studies have investigated how and why it contributes to entrepreneurship training. For example, Cyert and Goodman (1997) used organizational learning theory to developed a basic framework for examining university-industry collaboration in education. They argue that the fundamental benefit of collaboration between university and industry is learning from each other. The university can obtain methods and practices used in industry and industry can study the university's technology, and such interactions should be facilitated to enhance innovation. Thus, Cyert and Goodman argue, the educational program should be designed to foster mutual learning between the university and industry. Indeed, in past qualitative studies, such interactions between university members and industrial practition- 


\title{
A University-Industry Collaborative Entrepreneurship Education Program
}

\author{
Koichi Nakagawa, Megumi Takata, Kosuke Kato, Terumasa Matsuyuki, and Toshihiko Matsuhashi
}

ers were often discussed as a chief characteristic of university-industry collaboration as an educational approach (Borrell-Damian et al., 2010; Dooley \& Kirk, 2007).

The literature lacks detailed investigations regarding the exchange of knowledge through university-industry collaboration for the purposes of education, especially in the context of entrepreneurship. Past studies have largely been qualitative or conceptual have only described entrepreneurship education through university-industry collaboration in general. The research area lacks empirical evidence of the effect of the knowledge exchange on the capabilities of participants, and we do not have a framework that shows how it can be achieved and facilitated university-industry collaboration within an education program.

Given this gap in theoretical and practical knowledge, we set out to examine the case of Osaka University by asking: How can participants in an entrepreneurship education program based on university-industry collaboration effectively exchange heterogeneous experiential knowledge with each other despite differences in their disciplines, skills, and motivations?

\section{Research Method: Insider Action Research at Osaka University}

This study is based on an inductive case study of the Global Technology Entrepreneurship and Commercialization (G-TEC) program at Osaka University from 2011 to 2016. Considering our question has an open-ended, "asking-how" nature, an explorative case approach is a suitable approach because it can generate insights from the in-depth description (Eisenhardt, 1989; Yin, 1994). Data covering the G-TEC program was gathered from insider action research (Brannick \& Coghlan, 2007; Roth et al., 2007). We chose the insider action research method because being part of an extraordinary setting helps the researcher to precisely capture and describe what happens in within it. Two of the authors have engaged in developing the G-TEC program from the beginning and have worked as program facilitators in every year of its operation. The other two authors joined the study as observer-facilitators just after the start of the program. The last author analyzed the GTEC program objectively as an external observer. This team structure was adopted to ensure the richness of the description and endow diverse viewpoints, while maintaining objectiveness.
In addition to the qualitative analysis, we executed statistical analysis of a set of questionnaires completed by G-TEC participants in 2012 and 2013. We first asked participants to complete the questionnaire before GTEC program, to understand their initial capability in technological venturing. Then, we asked them to complete the questionnaire again after the program, to check what capability they had acquired through the program. We gave questionnaires to all 50 participants during those two years, and 48 (96\%) completed both "before and after" questionnaires. Within the questionnaire, we asked program participants about their perceived capability in technology venturing. Respondents were asked to answer each item using a five-point Likert scale that ranges from " 1 : I do not have that skill at all" to "5: I have that skill a great deal". Although we note that the resulting answers only provide the participants own perceptions about their capability, they nonetheless give an important indication of the changes in the participants' perceptions. Considering the emotional, psychological, and motivation-based nature of entrepreneurship (Drucker, 2014; Timmons \& Spinelli, 1999), a change in perception is a useful indicator of the participant's progress.

\section{The Global Technology Entrepreneurship and Commercialization (G-TEC) Program}

This study analyzes the G-TEC program at Osaka University as a research site. The program is a typical example of university-industry collaboration for entrepreneurship education. It has operated on a yearly basis since 2011. It is a short-term program that is delivered over the course of 2 weeks ( 8 hours per day over 10 days) with a course fee around \$2,500 USD. About 20 people participate in one instance of the program; thus, more than 100 students have completed the program. As its name indicates, the Technology Entrepreneurship and Commercialization program is designed to endow in its participants a capability around fundamental methods of technology entrepreneurship and commercialization.

Although the fundamental direction and methodology have been kept unchanged, the details of the program have been refined step by step. The program was initially openly advertised to both for university students and lecturers and corporate practitioners, and the number of applications regularly exceeded the capacity of the program. Rather than simply accept participants on a "first come, first served" basis, the program facilitat- 


\title{
A University-Industry Collaborative Entrepreneurship Education Program
}

\author{
Koichi Nakagawa, Megumi Takata, Kosuke Kato, Terumasa Matsuyuki, and Toshihiko Matsuhashi
}

ors decided to select participants through interviews in which they ask about the motivation, basic problemsolving skills, and past experiences of the applicants. Every year, the program staff have carefully balanced the diversity of participants at the time of recruitment, resulting in a nearly equal overall representation of university-based participants such as students or lecturers (44\%) and participants from industry (56\%). With each category, the participants have diverse experiences and skills. The students and lecturers have come from all kinds of schools including the social sciences, natural sciences, and humanities; the practitioners have come from engineering, manufacturing, sales and marketing, and the general administrative departments of several industries including the pharmaceutical, information technology, and electronics industries.

The G-TEC program was designed to integrate technological incubation and entrepreneurship education. It was co-designed by the office for university-industry collaboration and Professor Ashley Stevens from Boston University, who was then President of the Association of University Technology Managers. The design of the program recognizes that experiential learning is needed to develop true entrepreneurial skills and spirit, and such an educational grounding has often accelerated the commercialization of technologies. During the morning sessions of the program, the participants take classes about technology assessment, fundamental steps toward commercialization, entrepreneurship, market and competition analysis, intellectual property rights, technology development methodology, business model generation, financial forecasting, and funding strategies. In the afternoon, participants are challenged to make a technology assessment report and a strategic plan to achieve product completion and commercialization. At first, potential technologies within the university are provided by university-industry collaboration. A few university-based participants and a few industry-based participants form a cross-boundary team and tackle the assessment of one technology. More than $60 \%$ of the entire program is dedicated to building the assessment and commercialization plan report, including the relevant coursework as well as practical activities for commercialization and a field-based survey. We believe that the G-TEC program provides a suitable context to consider the theoretical model of an education program based on university-industry collaboration, because it includes its standard (but advanced) characteristics such as intellectual property assessment, technology marketing and licensing, proof of concept, business modelling, business planning, and so on. Given that the G-TEC program is designed from the benchmarking of the programs that were recognized as successful examples of university-industry collaboration, such as the University of Texas Austin and Boston University, it can be considered a tailored replication. The program was slightly modified in order to fit with the context of Japan, where people are often less inclined toward risk taking and opportunity seeking.

\section{Details of the G-TEC program}

In the G-TEC program, university-based participants learned from discussion with the business participants the reality of how to develop technology and products in private companies. They learned the importance of financial estimation, how cost and speed are crucial to market success, and how market demand is essential in commercialization. In addition, participants from the university also learned that sometimes a project must be abandoned if it proves unfeasible in terms of time, cost, or product quality. In the G-TEC program, the technology assessment often resulted in a tragic conclusion: scarce opportunities in the market, excessive development costs, or the discovery of more desirable technology. However, such conclusions nevertheless gave insights about the methodology of commercialization. Participants learned that the choice of technology is a vital aspect of reaching the market.

Project-based, experiential learning facilitated those practical methods and the understandings about the reality of technology commercialization. Students not only observed the practitioners' approaches but also tried to replicate them in the G-TEC program's joint project. By doing so, students learned those methods, which became tools that they could draw upon in the future. As one student participant noted in 2011:

"The greatest change for me was to first consider
the business model when evaluating a potential
technology. In the past, I only saw technology from
its own technological viewpoint. However, after the
collaboration with practitioners in G-TEC, I came
to think of the business aspect. When I listened to
the conference presentation about certain technolo-
gical areas, every participant exclusively discussed
technological features and challenges, while I con-
sidered who would be customers of that technology."

In addition, university-side participants learned the importance of humanity in entrepreneurial activities. In the business entities, contrary to the students' perspective, members act not only with the rationality of business but also with human feelings. Humanity becomes rather important to realize good progress in a project, 


\title{
A University-Industry Collaborative Entrepreneurship Education Program
}

\author{
Koichi Nakagawa, Megumi Takata, Kosuke Kato, Terumasa Matsuyuki, and Toshihiko Matsuhashi
}

because it endows members with a project mission that tackles a social problem, and it also facilitates in-depth communication with members that have diverse backgrounds (Hindle, 2007). Participants were often motivated by such a noble mission and realized good progress in developing the commercialization plan for the technology. Students were impressed by the challenging spirit that industry-side participants showed in the projects. Their high motivation guided teams toward the goal intensively, and students learned that this is a key success factor in entrepreneurial activities. As one student participant noted in 2013:

"I was impressed by the attitude of the practitioners toward the work. From their behaviour, I recognized the importance of the shared vision and the mutual trust within a project team. Conversation is critical to assess and develop the potential of the technology, and the vision and trust emerge from such conversations."

Participants from the industry side, on the other hand, learned theories and frameworks about technology development and commercialization from the instructors and university-based participants (Galloway \& Brown, 2002). This information included management theories for strategy, finance, and marketing as well as theories and methods about technological innovation and venturing that were provided in the courses of the university. By obtaining each knowledge component of technology and venture development, they captured the panoramic view of the venturing process from technical seed generation to commercialization. Industryside participants began to change their everyday behaviour at work in response to the insights from the theoretical viewpoint they received in the G-TEC program. As one corporate participant noted in 2013:

"I'm working as an engineer in a company. In this program, I learned skills to develop technology from the customer's viewpoint. I studied marketing theory and methods as well as market-oriented technology management in G-TEC. It was when I returned to my company than I truly understood the usefulness of what I had studied. I attended a technological conference held in New York as the company's representative. Although I had given presentations about our technology at past conferences, this time I found I could communicate with foreign engineers about how to solve their business problems using our technologies. Furthermore, I

\author{
realized that I could collect information about po- \\ tential markets for our technology while at that \\ conference."
}

Corporate-side participants learned the power of adopting a different viewpoint. Within the program, students often threw them innocent questions about the nature of the technology, business, and corporation. From those questions, practitioners sometimes recognized that their thinking was biased by their surroundings, whether it was competition, customers, colleagues, or even their boss. They then found that they could change the technology development policy or commercialization plan based on the insights from those innocent questions. Such occasions made them understand the power of diversity, which generates various ideas from different viewpoints. As one corporate participant noted in 2013:

"Group work with Osaka University students
was exciting. Through the discussions I had with
them, I recognized that my thinking, which was
derived from my usual work in the company, was
a little bit biased. The curiosity of the student-side
participants gave me a hint. They asked questions
about things that I thought of as common sense.
But through the debate with students, I found
that, for some of them, this way of thinking was
not rational. Based on that experience, I learned
the importance of doubting common sense and
searching for new ideas from a wide range of view-
points."

The role of program faculty and facilitators

The G-TEC program facilitators, which consist of three university lecturers and two office staff, represent the infrastructure of the program. The university lecturers have academic expertise in the areas of business management and have taught innovation management in the business school. One of them has a key role in offering in-class education in the morning sessions and is supported by the two other lecturers. The office staff basically work as facilitators of the technology assessment project, drawing upon their rich experience in developing technology and businesses in addition to academic credentials and experience in university-industry coordination. They also provided introductory instruction for team projects, including how to study, how to cooperate with each other, how to use relevant tools and utilities, and how to foster the spirit required for technological commercialization. 


\title{
A University-Industry Collaborative Entrepreneurship Education Program
}

\author{
Koichi Nakagawa, Megumi Takata, Kosuke Kato, Terumasa Matsuyuki, and Toshihiko Matsuhashi
}

In the words of one of the facilitators, the faculty and facilitators work to create a "shared language" for the diverse participants. The faculty and staff recognize that a shared language was important to execute the project work, particularly because it helped the participants share their ideas about technology commercialization more efficiently. Introductory instruction, as well as subsequent lectures, contributed to building up both a shared language and a shared cognition of participants.

Aside from delivering the classroom material and providing introductory information, the faculty and staff tried to limit their interference with each team's project work - they allowed the learning to emerge from the participants' experiences. Both success and failure provided opportunities for learning, so the faculty and staff simply provided opportunities for experiential learning and - as much as possible - left it to the participants to decide which opportunities to pursue and how. Only when the participants seemed "stuck" and were unable to progress with a project did the faculty or staff enquire about the problem and offer advice on how to improve the situation.

\section{Findings}

\section{Independence and temporary nature of the project}

Some participants emphasized that the program allowed them to experiment and explore opportunities that would not have been possible in their companies or university. Many of them joined the program because they were interested in new methodologies of commercialization or business development, but found it difficult to apply those methodologies in their company. After completing the program, many felt they had the knowledge, confidence, and legitimacy to try new things once they returned to their usual work, as one corporate participant noted in 2014:

\section{"I really enjoyed it. I could try what I could not do in my department. In G-TEC, I could act freely, without considering any risks and stakeholders in the company. I could focus my effort and attention on research and planning of the project. I could ap- ply some methodologies that I had learned not only in the program, but also from books I had read in the past."}

The independence and temporary nature of G-TEC program seemed to encourage a spirit of exploration among the participants. The program gave them a sense of freedom because it is totally independent from their everyday work or study, thus participants could act without thinking about how they might be judged by their boss, colleagues, customers, or human resources department. In addition, the short, two-week duration of the G-TEC program was beneficial. Although participants kept in touch with each other after the program, it basically did not affect their usual work, other than the small number of cases where participants have formed a venture business after the program. Furthermore, the limited timescale made it easier for companies to send participants, whether it was the employees needing to obtain permission to take time off work for the program or joining the program at the behest of their bosses.

Finally, the independence and temporary nature of the program had a positive effect on the participants' motivation. Participants recognized it as a special occasion to study novel ideas and new ways of thinking, apart from their usual work. They felt compelled to take advantage of a unique opportunity.

\section{Changes in capability}

To confirm our qualitative observations, we next examined the results of our survey of participants in the G-TEC program. As explained above, the survey asked participants about their perceived capability in technology venturing, both before and after the program. Table 1 shows the quantitative comparison of the perceived capability change between student participants and practitioner participants. The results show that students and practitioners benefitted differently from the program: the university students gained more business skills and external collaboration skills than participants from the industry, whereas industry participants obtained more technology development and commercialization methodology skills and more skills for team building than the university students. In other words, student participants learned in the program what they could not learn in their usual university education: business skills and external collaboration skills. Practitioner participants, in contrast, obtained knowledge about the methodology of technology development and commercialization, which are taught formally in universities. Furthermore, the data indicated that practitioners understood the importance of a diversity of team members for generating unique ideas. These quantitative results provide evidence that the exchange of knowledge worked in the G-TEC program, and they are in line with our qualitative observations. 


\section{A University-Industry Collaborative Entrepreneurship Education Program}

Koichi Nakagawa, Megumi Takata, Kosuke Kato, Terumasa Matsuyuki, and Toshihiko Matsuhashi

Table 1. Comparison of the capability change between 18 student participants and 30 practitioner participants of the G-TEC program. The bold and shaded text highlights the group with the larger improvement in perceived capability for each category.

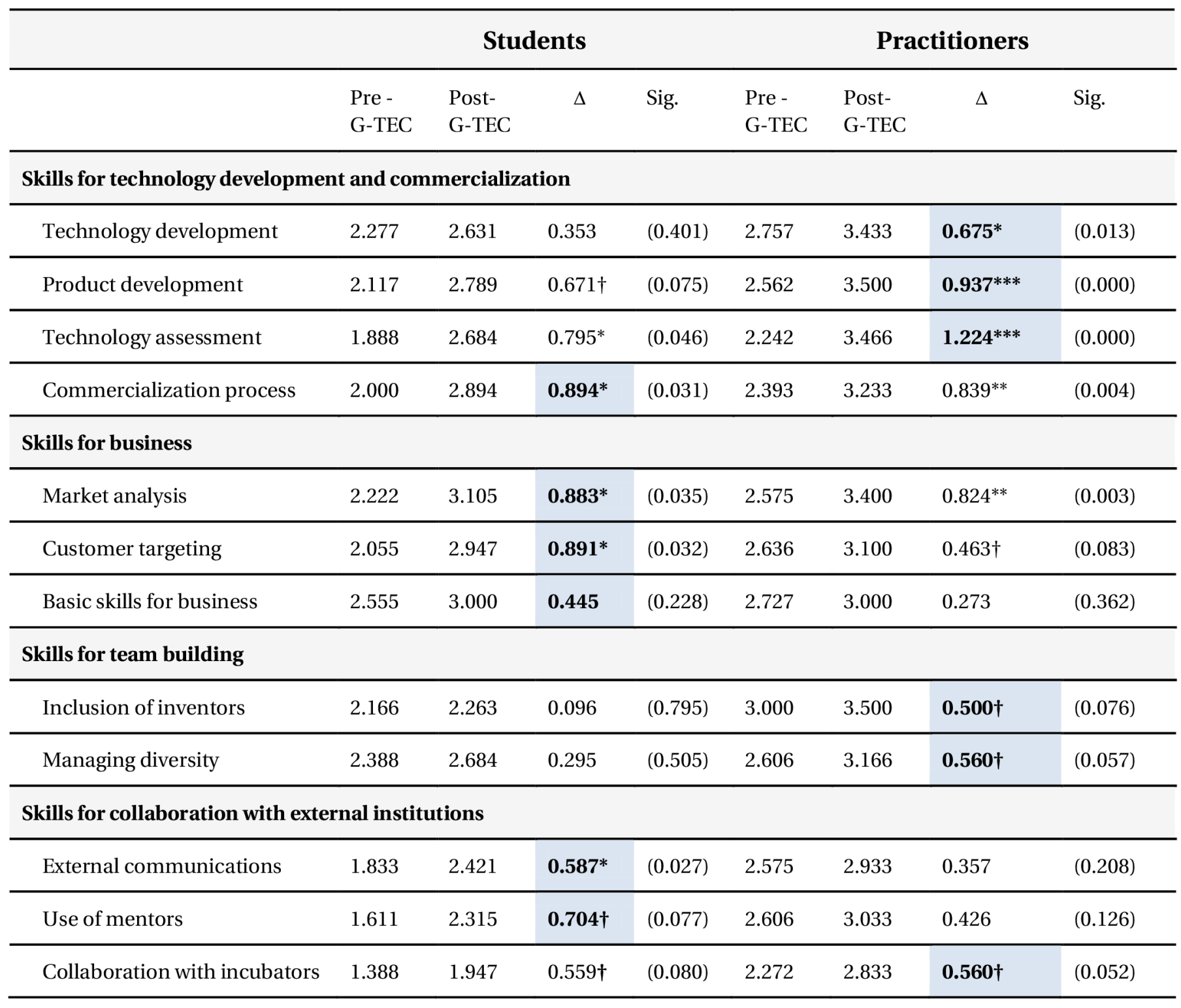

Significance in T-test (all two-tailed): $\dagger<0.1,{ }^{*}<0.05,{ }^{* *}<0.01,{ }^{* * *}<0.001$. 


\title{
A University-Industry Collaborative Entrepreneurship Education Program
}

\author{
Koichi Nakagawa, Megumi Takata, Kosuke Kato, Terumasa Matsuyuki, and Toshihiko Matsuhashi
}

\section{Discussion}

From the case analysis, we confirmed that knowledge exchange actually happened between university students and practitioners within the G-TEC program, and that it is promoted by program facilitators and the program's "special atmosphere" and conditions of this short-duration program. Students learned managerial skills and gained an entrepreneurial mindset from their interactions with the practitioner participants and by observing their behaviour and ways of thinking. The practitioners learned academic knowledge and frameworks for entrepreneurship from the students and the faculty. This knowledge-level interaction could be considered as one of the core contributions of education through university-industry collaboration. To build up entrepreneurship skills and spirit, both theoretical and experiential learning are desirable (Dooley \& Kirk, 2007; Ollila \& Williams-Middleton, 2011). In this sense, this form of collaborative education is effective because it can provide experiential know-how for students and theoretical knowledge for practitioners. Based on past conceptual studies (e.g., Cyert \& Goodman, 2007) and our evidence that the exchange of knowledge actually occurred in education through university-industry collaboration, we offer the following proposition:

Proposition 1: Education for technological entrepreneurship based on university-industry collaboration is characterized by the exchange of knowledge among different groups: faculty members, practitioners, and university students.

In examining this exchange of knowledge through our observations of the G-TEC program, we apply the metaphor of a "trading zone". The basis of the metaphor is anthropological studies by Galison (1997, 1999), who examined how different cultures are able to exchange knowledge in temporary projects. Galison found that members from different communities were able to exchange their knowledge despite having fundamental differences (Galison, 1997). To enact a trading zone does not require equivalence of interests or interpretations. Furthermore, even the permanence of relationships is not needed to work in a trading zone. Participants from different organizations coordinate their behaviours temporarily and locally, navigating their different norms and interests as needed (Kellogg et al., 2006; Vaughan, 1999). Such descriptions are quite consistent with the situation in the G-TEC program. Participants exchanged knowledge from different motivations and disciplines within a temporary project of cross-boundary coordination. Thus, we set the trading zone as a framework for entrepreneurship education through university-industry collaboration.

With the help of the trading zone metaphor, we can indicate that the exchange happens when project teams have heterogeneous skills and mindsets. As our statistical examination and case description showed, students learned business skills and external partnership skills that they did not have previously, but were already possessed by the practitioners before the program started. Similarly, practitioner participants learned basic theory about technological development and commercialization that the students and faculty had had but the industry participants did not. Considering those results, we can say that trading happens because the two groups have different assets to offer. Thus, our next proposition is as follows:

Proposition 2: The exchange of knowledge in education for technological entrepreneurship through university-industry collaboration is derived from the heterogeneity of practitioners and students.

Next, we analyze the consequences of that "trade." As past studies have shown, a trade does not mean a simple transfer of knowledge. Rather, it brings significant restructuring of each participant's body of knowledge through the combination of new and existing knowledge (Galison, 1997; Kellogg et al., 2006). Kellogg, Orlikowski, and Yates (2006) indicated from their analysis of cross-boundary coordination in a marketing project that the exchange between members brought ongoing revision of the work and their understandings. Our observation is in accordance with their findings: both students and practitioners refined their understanding of technology commercialization and what aspects should be considered important. Such restructuring of the body of knowledge would be the central contribution of education for entrepreneurship education through university-industry collaboration. It was not the simple collection of participants' skills and knowledge, but the integration of them, which leads to our next proposition:

Proposition 3: Participants of education for technological entrepreneurship through university-industry collaboration restructure their body of knowledge through their interactions with participants from different organizations.

The role of the faculty and facilitation staff should also be considered when attempting to understand the mechanism of this trading zone. In our observations, 


\title{
A University-Industry Collaborative Entrepreneurship Education Program
}

\author{
Koichi Nakagawa, Megumi Takata, Kosuke Kato, Terumasa Matsuyuki, and Toshihiko Matsuhashi
}

faculty members provided access to a body of knowledge about technology commercialization, and facilitators provided an introduction to the group project. Both of them encouraged teams to communicate effectively to find a solution, and they committed the participants to that problem-solving effort. From the viewpoint of a trading zone, the role of program facilitators could be a mediator or an agent of the exchange. They usually kept silent as long as the interactions between participants were proceeding smoothly. However, when needed, the program facilitators were able to intervene to get the teams back on track. Furthermore, introductory instruction by the facilitators provided the shared language used in the projects, which made it easier for participants to understand each other's ideas and opinions. Based on this interpretation of our results, we offer the following propositions about the role of facilitators:

Proposition 4a: The faculty of an education program for technological entrepreneurship through university-industry collaboration provide fundamental knowledge to both practitioners and university students.

Proposition 4b: Facilitators of an education for technological entrepreneurship through university-industry collaboration work as mediators in the exchange of knowledge.

Finally, we consider the effect of the temporary nature of the education program. In our observations, participants showed high motivation for the project work and were stimulated by the unique situation. Student participants felt that the G-TEC program was a special occasion, because it gave them the chance to meet skillful practitioners, to show their ability in technology commercialization, and to find an opportunity for venturing. Similarly, practitioner participants saw the GTEC program as a precious opportunity to study at university again, to meet highly educated students and professors, and to try new things that could not be permitted within their companies. The G-TEC program worked as a "trading zone" that was a special place for knowledge exchange. It was independent from the participants' ordinary jobs or studies, thus they were allowed to undertake bold challenges without risk, and they felt more motivated than usual. The extraordinary and temporary nature of the program heightened the learning performance of the participants, and leads us to the following proposition:

\begin{abstract}
Proposition 5: An extraordinary and temporary context can activate participant learning in education through university-industry collaboration.
\end{abstract}

In Figure 1, we summarize our findings into one picture that describes the overall model of education through university-industry collaboration from the viewpoint of the trading zone metaphor. The G-TEC program is a temporary, extraordinary context that facilitates interactions between practitioners and students. Studentside participants and industry-side participants exchange assets with each other: students brought academic theory and framework, innocent and unbiased viewpoints, and the academic mindset. Practitioners brought practical know-how, realistic views of business, and a challenging spirit for commercialization. The heterogeneity among participants became the basis for knowledge exchange, while program lecturers and staff established a shared language to facilitate the interaction. This trading zone can be proposed as a potential framework for technology entrepreneurship education through university-industry collaboration.

\section{Conclusion}

As reviewed above, there are few studies about university-industry collaboration for education, despite the attention being paid to university-industry collaboration in general (Perkmann \& Walsh, 2007). Based on a case description and analysis of the G-TEC program at Osaka University in Japan, we introduced the trading zone (Galison, 1997; Vaughan, 1999) as a potential framework for the exchange of knowledge between groups. It provides a viewpoint that, in a cross-border project, the exchange of knowledge happens between heterogeneous members under the extraordinary and temporary conditions. Each member transacts with their own interests, and the result is improved knowledge for every participant. We believe our work can form a basis for analyzing and discussing this style of education through university-industry collaboration.

Our findings have practical implications for the designers or managers of entrepreneurship education programs. Our analysis indicates that diversity among participants is critical to the education performance of the G-TEC program. Program staff should mediate and facilitate the interaction with those diverse participants, and the program should nurture a feeling of freedom and an appreciation for its extraordinary context. 


\section{A University-Industry Collaborative Entrepreneurship Education Program}

Koichi Nakagawa, Megumi Takata, Kosuke Kato, Terumasa Matsuyuki, and Toshihiko Matsuhashi

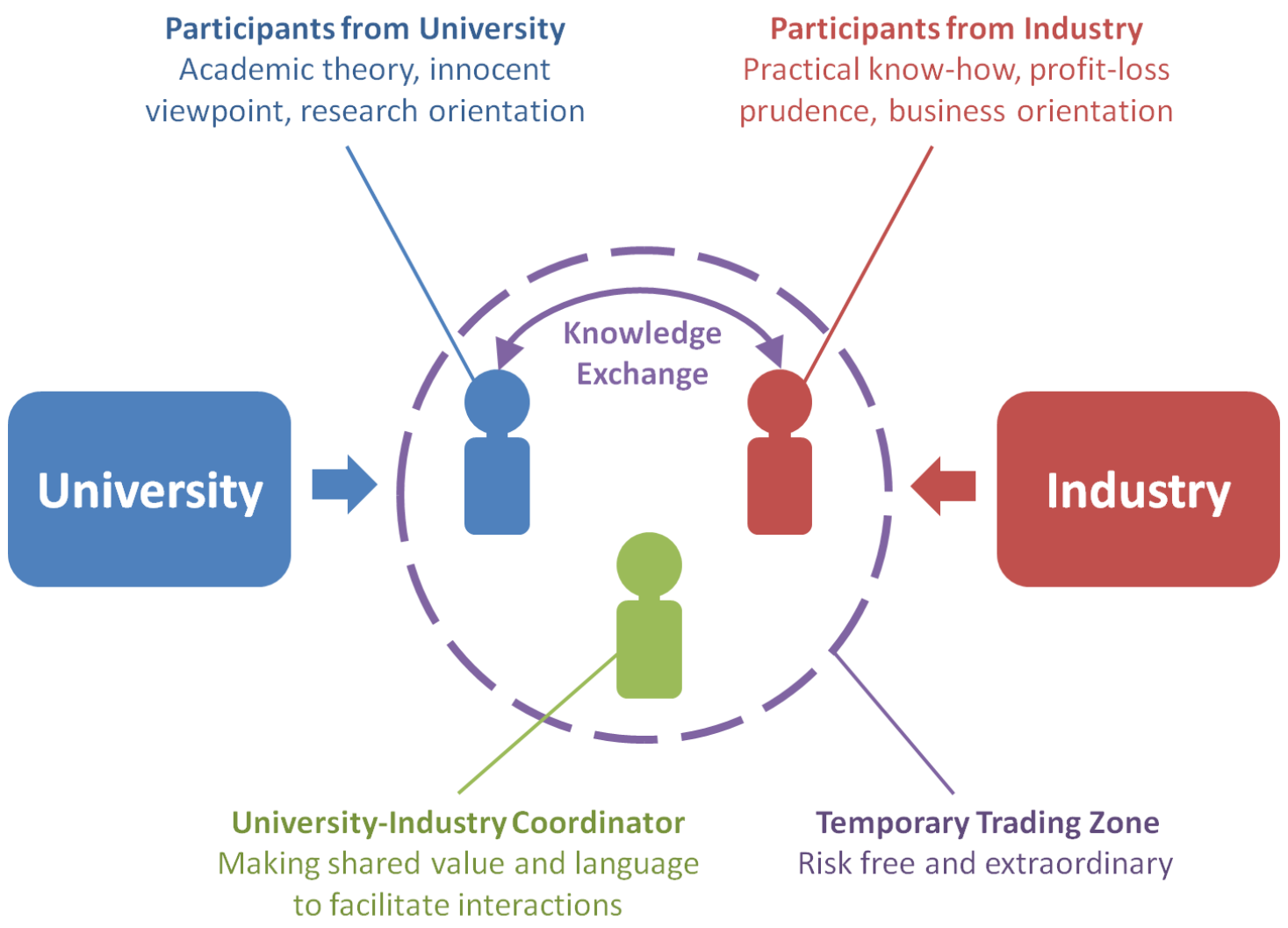

Figure 1. The "trading zone" framework: technology entrepreneurship education through university-industry collaboration

However, our findings are limited in the extent to which they can be generalized. The applicability of our findings must be constrained in terms of external validity, given that this study is based on single case analysis. Ideas from the G-TEC program and the trading zone metaphor should be examined in future studies and with more samples. However, our findings do have some scope for generalizations given that our research site and the G-TEC program has typical settings of education through university-industry collaboration, and the trading zone analogy is in line with past studies (e.g., Cyert \& Goodman, 1997; Dooley \& Kirk, 2007). Thus, we have offered several general propositions that might have generality. Although it must be tested in future research, the viewpoint of a trading zone for university-industry collaboration may benefit the progress of the study of entrepreneurship education.

\section{Acknowledgements}

This research was partially supported by JSPS Grant-inAid for Scientific Research (C), Grant number: JP26350237.

An earlier version of this article was presented at the ISPIM Innovation Forum in Toronto, Canada, March 19-22, 2017. ISPIM (ispim-innovation.com) - the International Society for Professional Innovation Management - is a network of researchers, industrialists, consultants, and public bodies who share an interest in innovation management. 


\section{A University-Industry Collaborative Entrepreneurship Education Program}

\section{Koichi Nakagawa, Megumi Takata, Kosuke Kato, Terumasa Matsuyuki, and Toshihiko Matsuhashi}

\section{About the Authors}

Koichi Nakagawa is an Associate Professor of the Graduate School of Economics at Osaka University, Japan. He received a $\mathrm{PhD}$ in Economics from The University of Tokyo. His academic works are mainly about the management of innovation, and his current interests focus on the key success factors for innovation in emerging situations, such as university-industry collaboration, post-corporate acquisition, and low-income countries. He works not only as an academician but also as a consultant of innovation and design management for private companies.

Megumi Takata is a Professor in the Department of Business and Technology Management within the Graduate School of Economics at Kyushu University in Fukuoka, Japan (Kyushu University Business School; QBS). Since 2010, he is also a faculty member of the Kyushu University Robert T. Huang/Entrepreneurship Center (QREC). Megumi is also a Registered Technology Transfer Professional since 2014. He holds a Bachelor of Engineering in Metallurgy and a Master in Architecture \& Regional Planning from Kyushu University. After several multi-year experiences as an engineer and consultant, in 1999 he joined CASTI, the technology licensing company of the University of Tokyo, as an Executive Vice President \& COO. He moved to QBS as an Associate Professor in 2003. He was also a Director of the Tech-Transfer Department of the Intellectual Property Management Center of Kyushu University from 2003 to 2010.

Kosuke Kato currently serves as the Head of the Planning Section in the Co-Innovation Division of the Office for Industry-University Co-Creation at Osaka University, Japan. He has also served as an Associate Professor in the Management of Industry and Technology Division of the Graduate School of Engineering at Osaka University. He has published a peer-reviewed article in Journal of the Licensing Executives Society International (JLESI) on the topic of technology transfer. Kosuke received his PhD in Science and Technology from Kumamoto University and performed research in the area of human informatics. He has published multiple articles in peer-reviewed journals, for example, on the topic of the sensory-motor integration of musicians. He also holds an MS degree in Architectural Engineering from Kobe University. He completed the Technology Transfer Fellowship program offered by Boston University's Office of Technology Development and has been globally recognized as a Registered Technology Transfer Professional since November 2013.

Terumasa Matsuyuki is Visiting Associate Professor in the Office for Industry-University Co-Creation at Osaka University, Japan. His research fields are microeconomic theory, industrial organization, and entrepreneurship. He teaches classes on entrepreneurship technology entrepreneurship, international business and standardization, social design, science, technology and social enterprise, leadership and management, practicing global leadership, among others. He has been a committee member of innovation programs such as the CrossBoundary Innovation Program and the EDGE program at Osaka University. He is one of the core members in entrepreneurship education at Osaka University and organizes the Entrepreneurship Speaker Series. He offers many workshops on ideation, design thinking, and behaviour observation. His previous positions include Associate Professor in the Center for Liberal Arts and Sciences at Osaka University, Lecturer at Yokohama National University, and Visiting Scholar at Toyo University.

Toshihiko Matsuhashi is a specially appointed Professor for University-Industry Co-Innovation at Osaka University, Japan. He graduated from Kyoto University with a Bachelor of Engineering, and he received an MBA from Boston University in the United States. He has been engaged in making and supporting strategic collaborations for innovation between industry and academia and with the incubation of startups at Osaka University. He has over 23 years of business experience, including strategic consultation for a hospital management company and strategic planning, technology management, and new business creation at a global electronics company. 


\section{A University-Industry Collaborative Entrepreneurship Education Program Koichi Nakagawa, Megumi Takata, Kosuke Kato, Terumasa Matsuyuki, and Toshihiko Matsuhashi}

\section{References}

Barr, S. H., Baker, T. E. D., Markham, S. K., \& Kingon, A. I. 2009. Bridging the Valley of Death: Lessons Learned from 14 Years of Commercialization of Technology Education. Academy of Management Learning \& Education, 8(3): 370-388.

http://www.jstor.org/stable/27759173

Borrell-Damian, L., Brown, T., Dearing, A., Font, J., Hagen, S., Metcalfe, J., \& Smith, J. 2010. Collaborative Doctoral Education: University-Industry Partnerships for Enhancing Knowledge Exchange. Higher Education Policy, 23(4): 493-514. http://dx.doi.org/10.1057/hep.2010.20

Brannick, T., \& Coghlan, D. 2007. In Defence of Being "Native": The Case for Insider Academic Research. Organizational Research Methods, 10(1): 59-74.

https:// doi.org/10.1177/1094428106289253

Blumenfeld, P. C., Soloway, E., Marx, R. W., Krajcik, J. S., Guzdial, M., \& Palincsar, A. 1991. Motivating Project-Based Learning: Sustaining the Doing, Supporting the Learning. Educational Psychologist, 26(3-4): 369-398.

http://dx.doi.org/10.1080/00461520.1991.9653139

Cyert, R. M., \& Goodman, P. S. 1997. Creating Effective UniversityIndustry Alliances: An Organizational Learning Perspective. Organizational Dynamics, 25(4): 45-57. https://doi.org/10.1016/S0090-2616(97)90036-X

Dooley, L., \& Kirk, D. 2007. University-Industry Collaboration: Grafting the Entrepreneurial Paradigm onto Academic Structures. European Journal of Innovation Management, 10(3): 316-332. https://doi.org/10.1108/14601060710776734

Drucker, P. 2014. Innovation and Entrepreneurship. London: Routledge.

Eisenhardt, K. M. 1989. Building Theories from Case Study Research. Academy of Management Review, 14(4): 532-550. http://dx.doi.org/10.5465/AMR.1989.4308385

Etzkowitz, H. 2004. The Evolution of the Entrepreneurial University. International Journal of Technology and Globalisation, 1(1): 64-77. https://doi.org/10.1504/IJTG.2004.004551

Etzkowitz, H., \& Leydesdorff, L. 2000. The Dynamics of Innovation: From National Systems and "Mode 2" to a Triple Helix of University-Industry-Government Relations. Research Policy, 29(2): 109-123.

https://doi.org/10.1016/S0048-7333(99)00055-4

Galison, P. 1997. Image and Logic: A Material Culture of Microphysics. Chicago: University of Chicago Press.

Galison, P. 1999. Trading Zone: Coordinating Action and Belief. In M. Biagioli (Ed.), The Science Studies Reader: 137-160. London: Routledge.

Galloway, L., \& Brown, W. 2002. Entrepreneurship Education at University: A Driver in the Creation of High Growth Firms? Education+ Training, 44(8/9): 398-405. https://doi.org/10.1108/00400910210449231
Heinonen, J., \& Poikkijoki, S. A. 2006. An Entrepreneurial-Directed Approach to Entrepreneurship Education: Mission Impossible? Journal of Management Development, 25(1): 80-94. https://doi.org/10.1108/02621710610637981

Hindle, K. 2007. Teaching Entrepreneurship at University: From the Wrong Building to the Right Philosophy. In A. Fayolle (Ed.), Handbook of Research in Entrepreneurship Education, 1: 104-126. Cheltenham, UK: Edward Elgar Publishing.

Janssen, F., Eeckhout, V., \& Gailly, B. 2007. Interdisciplinary Approaches in Entrepreneurship Education Programs. In A. Fayolle (Ed.), Handbook of Research in Entrepreneurship Education, 2: 148-165. Cheltenham, UK: Edward Elgar Publishing.

Kellogg, K. C., Orlikowski, W. J., \& Yates, J. 2006. Life in the Trading Zone: Structuring Coordination across Boundaries in Postbureaucratic Organizations. Organization Science, 17(1): 22-44. https://doi.org/10.1287/orsc.1050.0157

Lundqvist, M. A., \& Williams Middleton, K. L. 2013. Academic Entrepreneurship Revisited - University Scientists and Venture Creation. Journal of Small Business and Enterprise Development, 20(3): 603-617. https://doi.org/10.1108/JSBED-04-2013-0059

Meyer, A. D., Aten, K., Krause, A. J., Metzger, M. L., \& Holloway, S. S. 2011. Creating a University Technology Commercialisation Programme: Confronting Conflicts between Learning, Discovery and Commercialisation Goals. International Journal of Entrepreneurship and Innovation Management, 13(2): 179-198. https://doi.org/10.1504/IJEIM.2011.038858

Ollila, S., \& Williams Middleton, K. 2011. The Venture Creation Approach: Integrating Entrepreneurial Education and Incubation at the University. International Journal of Entrepreneurship and Innovation Management, 13(2): 161-178. https://doi.org/10.1504/IJEIM.2011.038857

Perkmann, M., \& Walsh, K. 2007. University-Industry Relationships and Open Innovation: Towards a Research Agenda. International Journal of Management Reviews, 9(4): 259-280. http://dx.doi.org/10.1111/j.1468-2370.2007.00225.x

Rasmussen, E. A., \& Sørheim, R. 2006. Action-Based Entrepreneurship Education. Technovation, 26(2): 185-194.

https://doi.org/10.1016/j.technovation.2005.06.012

Roth, J., Shani, A. B. R., \& Leary, M. M. 2007. Insider Action Research Facing the Challenges of New Capability Development within a Biopharma Company. Action Research, 5(1): 41-60. https://doi.org/10.1177/1476750307072875

Timmons, J. A., \& Spinelli, S. 1999. New Venture Creation: Entrepreneurship for the 21st Century. New York: McGraw Hill.

Vaughan, D. 1999. The Role of the Organization in the Production of Techno-Scientific Knowledge. Social Studies of Science, 29(6): 913-943. https://doi.org/10.1177/030631299029006005

Yin, R. 1994. Case Study Research: Design and Methods. Beverly Hills, CA: Sage Publications. 